\title{
Regulation of Abiotic Stress Response Through NtROS2a-mediated Demethylation in Tobacco
}

\author{
In Hye Lee ${ }^{1 \dagger}$, Jang Sun Choi ${ }^{1 \dagger}$, Marjohn Nino $^{3}$, Yong-Gu Cho ${ }^{3}$, Kwon Kyoo Kang ${ }^{1,2 *}$, Yu Jin Jung ${ }^{1,2 *}$ \\ ${ }^{1}$ Department of Horticulture, Hankyong National University, Ansung 456-749, Korea \\ ${ }^{2}$ Institute of Genetic Engineering, Hankyong National University, Ansung 456-749, Korea \\ ${ }^{3}$ Department of Crop Science, Chungbuk National University, Cheongju 362-763, Korea
}

\begin{abstract}
DNA methylation is a common and rapid evolving epigenetic mechanism among higher eukaryotic organisms including cytosine residues in CG and CNG sequences. NtROS2a gene isolated from tobacco plants (Nicotiana tabacum cv Xanthi nc) contains DNA glycosylase domain with significant similarities to Arabidopsis ROS1 and DME at the C-terminus. Purified NtROS2a protein

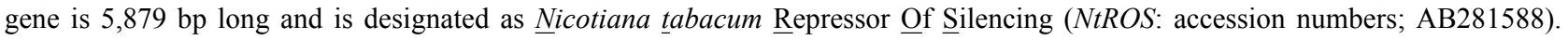
RT-PCR analysis initially revealed the adaptive response of the lines overexpressing the gene in tobacco to various abiotic stresses. This was validated when phenotypic evaluation to cold, salt, simulated drought and osmotic stress tolerance was performed. Reduction in leaf wilting rate against high salinity treatment is remarkable in transgenic plants which showed at least $50 \%$ less wilting than the WT. Moreover, about $70 \%$ wilt rate difference was noted between the transgenic and WT in $\mathrm{H}_{2} \mathrm{O}_{2}$ treatment. This study showed that NtROS $2 a$ gene encoding DNA glycosylase which caused demethylation could regulate adaptive response of tobacco to various abiotic stress conditions.
\end{abstract}

Keywords DNA methylation, Demethylation, Repressor of silencing, Nicotiana tabacum, Transgenic plant

\section{INTRODUCTION}

Epigenetics is a change in gene expression through chromatin modifications without base sequence alteration (Law and Jacobsen 2010), which facilitates recruitment of the RNA polymerase II transcriptional machinery to the promoter. This frequently occurs during somatic cell differentiation, in which the clonal expansion of a single cell leads to a diversity of cell types (Zhang et al. 2006). Such a cellular inheritance is common during ontogeny but is usually erased before gametes are produced (Reik and Walter 2001). In eukaryotes, DNA methylation has important roles in the establishment of developmental programs in fungi, plants, and animals. DNA methylation of mammalian and plant is restricted to symmetrical $\mathrm{CpG}$ sequences, but plants also have significant levels of cytosine methylation in the symmetric context $\mathrm{CpNpG}$ (where $\mathrm{N}$ is any nucleotide), $\mathrm{CpNpN}$ ( $\mathrm{N}$ is $\mathrm{A}, \mathrm{T}$ or $\mathrm{C}$ ) and even in a symmetric contexts (Bird 2002). DNA methylation is associated with numerous functions, depending on the model organism and the environment component. In the experiment involving mice, DNA methylation has been shown to be essential for proper embryonic development (Li et al. 1992). Similarly, a loss of DNA methylation caused developmental defects in Xenopus embryos (Stancheva and Meehan 2000). In parallel with plants, reduced levels of DNA methylation were shown to be responsible for a large number of developmental abnormalities (Finnegan et al. 1996; Ronemus et al. 1996; Cao and Jacobsen 2002; Kankel et al. 2003). The triple mutant that lacks DRM1, DRM2, and CMT3, which has greatly reduced non-CG methylation (Cao and Jacobsen 2002) and the mutant that

Received June 5, 2015; Revised June 15, 2015; Accepted June 22, 2015; Published June 30, 2015

*Corresponding author Kwon Kyoo Kang, kykang@hknu.ac.kr, Tel: +82-31-670-5104, Fax: +82-31-670-5109

*Corresponding author Yu Jin Jung, yuyu1216@hknu.ac.kr, Tel: +82-31-670,5101, Fax: +82-31-670-5109

${ }^{\dagger}$ These authors contributed equally to this work.

*To whom co-correspondence should be addressed. 
lacks MET1, in which both CG and, to a lesser extent, non-CG methylation are decreased. Superficial similarities in some of the developmental defects have been interpreted to reflect a conserved function of DNA methylation. However, the molecular consequences of genomic DNA methylation have been found to be surprisingly diverse and broad (Cao and Jacobsen 2002; Kankel et al. 2003). However, unlike methylation, studies on de-methylation are still limited. In contrast to the well-studied genetics, biology and biochemistry of cytosine DNA methyltransferases, the enzymatic basis of active demethylation have remained elusive (Morales-Ruiz et al. 2006). Direct removal of the methyl group from 5-meC residues has been reported, but this mechanism, which involves a thermodynamically unfavorable breakage of the carbon-carbon bond, has been questioned and could not be independently reproduced (Agius et al. 2006). Recent work in plants has added genetic evidence for a role of DNA glycosylases in an active demethylation pathway. In Arabidopsis, recent genetic and biochemical studies demonstrated that two bifunctional DNA glycosylase/lyases, ROS1 and Demeter, function as DNA demethylase (Gehring et al. 2006; Agius et al. 2006; Morales-Ruiz et al. 2006). ROS1 can specifically recognize methylated DNA substrate. Its glycosylase activity removes the 5-methylcytosine base, and its lyase activity nicks the DNA backbone at the abasic site by $\alpha, \beta$ elimination mechanism (Agius et al. 2006; Morales-Ruiz et al. 2006). Methylation status dynamically changes depending upon cell type, developmental stages and even environmental conditions (Demeulemeester et al. 1999; Steward et al. 2002; Chakrabarty et al. 2003; Wada et al. 2004). First, because DNA methylation in nucleosomes induces alteration of gene expression by changing chromatin structures; vast demethylation may serve as a common switch for many genes that are simultaneously controlled upon environmental cues. Second, because artificial demethylation induces heritable changes in plant phenotype (Sano et al. 1990); altered DNA methylation may result in epigenetic inheritance, in which gene expression is modified without changing the nucleotide sequence. To investigate the function of NtROS $2 a$ gene encoding DNA glycosylase in various abiotic stress conditions, we developed transgenic tobacco plants using overexpression and RNAi technique and subjected them to cold, salt and heat stress.

\section{MATERIALS AND METHODS}

\section{Gene isolation and cloning}

Total RNA was isolated from tobacco samples by acid guanidium thiocyanate-phenol -chloroform (AGPC) method (Chomczynski and Sacchi 1987) with a slight modification, and used for cDNA library construction with the ZapII vector (Stratagene, La Jolla, CA, USA). In brief, cDNAs were ligated to the vector at the EcoRI and XhoI sites, and after transformation, the library was screened with 32Plabeled probes. Positive clones were rescued in the pBluescript SK-phagemid vector by in vivo excision, and amplified in Escherichia coli DH5a. The nucleotide sequences were determined by the dideoxynucleotide chain termination method (PRISM BigDye Terminator, ABI, Sunnyvale, CA, USA), and analyzed with appropriate computer software (GeneWorks, National Center for Biotechnology Information, and PSORT server). Genomic sequence was obtained by PCR using genomic DNA as the template and appropriate primer sets designed after the cDNA sequence. Resulting fragment was 10,243 bp, including a 1918 bp upstream region from the transcription initiation site (accession number AB267678).

\section{Ti-plasmid vector construction for plant transformation}

To produce transgenic plants carrying NtROS2a gene, the NtROS $2 a$ cDNA was ligated into the pBI121 and pKANNIBAL vector and electroplated into Escherichia coli strain XL10-Gold (Stratagene) resulting in $1.5 \times 10^{6}$ transformants. The construct was confirmed by PCR amplification using the $35 \mathrm{~s}$ promoter (F-5' TGAGACTTTTCAACAAAGGGTA), and NtROS2a (R-3' GGGAACTGATGAGCGGTTTG) primers. The construct was electroporated into Agrobacterium tumefaciens strain LBA4404 (Koncz and Schell 1986) and $2.6 \times 10^{6} \mathrm{cfu} / \mathrm{ml}$ inoculum was obtained 48 hours after shake-incubation of the bacteria in $25 \mathrm{ml} \mathrm{LB}$ medium at $240 \mathrm{rpm}$ speed at $28^{\circ} \mathrm{C}$ and stored in $50 \%$ glycerol at $-80^{\circ} \mathrm{C}$ until use. 


\section{Generation of NtROS2a transgenic tobacco}

Seeds of wild type tobacco were surface sterilized by washing with $70 \%$ ethanol for $1 \mathrm{~min}, 3 \%$ sodium hypochlorite for $10 \mathrm{~min}$, and rinsed four times with sterile distilled water. The seeds were then allowed to germinate in glass containers with $25 \mathrm{~cm}^{3}$ of MS-based medium (Murashige and Skoog 1962). For transformation experiments, tobacco was grown on MS medium in a Magenta culture box (Sigma, USA) in a culture room at $28^{\circ} \mathrm{C}$ under an $18 \mathrm{~h}$ (day) $/ 6 \mathrm{~h}$ (night) photoperiod. Sterile leaf disks were co-cultivated with Agrobacterium and planted onto a medium without antibiotics. After incubation at $28^{\circ} \mathrm{C}$ for two days, the leaf discs were transferred to MS medium supplemented with 6-benzylaminopurine (BA) $1 \mathrm{mg} / \mathrm{L}$ and 1-naphtalene acetic acid (NAA) $0.1 \mathrm{mg} / \mathrm{L}$ for callus and shoot induction. For root induction, MS medium containing hygromycin $50 \mathrm{mg} / \mathrm{L}$ was used. The media for callus and shoot, and root induction contained $8 \mathrm{~g} / \mathrm{L}$ of agar, $50 \mathrm{mg} / \mathrm{L}$ hygromycin and the cultures were maintained at $28^{\circ} \mathrm{C}$ under light condition. After root induction, putative transgenic plants were transferred immediately to MS medium without plant hormones.

\section{Genomic DNA isolation}

Total DNA of transgenic tobacco was extracted from a ground freeze-dried leaf tissue (200 $\mathrm{mg})$ using the cetyltrimethy1 ammonium bromide (CTAB) method. After adding the CTAB buffer, the samples were incubated in a $55^{\circ} \mathrm{C}$ water bath for $15 \mathrm{~min}$. After incubation, the extract mixture was spun at $1200 \mathrm{rpm}$ for $5 \mathrm{~min}$ and the supernatant were transferred into clean tubes and added with $250 \mu \mathrm{l}$ of chloroform: isoamy1 alcohol (25:1). The mixture was mixed gently by inverting for $5 \mathrm{~min}$ and was centrifuge at $13,000 \mathrm{rpm}$ for $3 \mathrm{~min}$ at room temperature. The aqueous phase were collected into a clean tube added with 0.08 vol. of cold $7.5 \mathrm{M}$ ammonium acetate and 0.8 vol. of cold isopropanol $\left(-20^{\circ} \mathrm{C}\right)$. The mixture was kept in the freezer for $30 \mathrm{~min}$, and the DNA was collected by centrifugation at $13,000 \mathrm{rpm}$ for $10 \mathrm{~min}$. The pellet was washed with $500 \mu \mathrm{l}$ $70 \%$ ethanol, air-dried and resuspended in 50-100 $\mu$ of $\mathrm{ddH}_{2} \mathrm{O}$.

\section{PCR analysis}

The presence of transgene in putative transgenic plants was detected by PCR method with $35 \mathrm{~S}$ promoter F-5' (5'-TGAGACTTTTCAACAAAGGGTA-3') and NtROS2a gene R-(5'-GGGAACTGATGAGCGGTTTG-3') primer pair. The assay was performed in a total $50 \mu 1$ volume containing $100 \mathrm{pg}$ DNA, 10 pmol each of primers, $2.5 \mathrm{mM}$ dNTPs, 10X PCR buffer, and 0.5 U Taq-polymerase (Takara, Japan). The PCR reaction was carried out by denaturing the template at $94^{\circ} \mathrm{C}$ for $5 \mathrm{~min}$ followed by 35 cycles of amplification $\left(1 \mathrm{~min}\right.$ at $94^{\circ} \mathrm{C}, 1 \mathrm{~min}$ at $50^{\circ} \mathrm{C}$ and 2 min at $72^{\circ} \mathrm{C}$ ) and by extension at $72^{\circ} \mathrm{C}$ for $5 \mathrm{~min}$.

\section{Gene expression analysis under the abiotic stresses}

Tobacco Seeds (Nicotiana tabacum cv Xanthinc) were grown under controlled conditions $\left(28^{\circ} \mathrm{C}\right.$ day $/ 25^{\circ} \mathrm{C}$ night temperatures, $14 \mathrm{~h}$ light $/ 10 \mathrm{~h}$ darkness, $75 \%$ relative humidity) in MS medium in a Magenta culture box (Sigma, USA). After three weeks of germination, seedlings were exposed to high-salinity $(250 \mathrm{mM})$, cold $\left(4^{\circ} \mathrm{C}\right), \mathrm{H}_{2} \mathrm{O}_{2}(3 \%)$, and $100 \mu \mathrm{M}$ ABA stresses. The plant tissues were harvested after $0,30 \mathrm{~min}, 6 \mathrm{~h}$, and $8 \mathrm{~h}$ of stress treatment, immediately frozen in liquid nitrogen, and stored at $-80^{\circ} \mathrm{C}$. Total RNA was extracted using Trizol reagent (Invitrogen, USA) according to the manufacturer's protocol. Real-time PCR was conducted using RT pre-mix (TOYOBO Co., Japan) in a Bio-RAD I Cycler IQ5 machine. The threshold cycle $(\mathrm{Ct})$ values of the triplicate PCRs were averaged and the relative quantification of the expression levels was performed using the comparative $\mathrm{Ct}$ method (Livak et al. 2001). The fold change in total RNA (target gene) relative to the reference gene (actin gene) was determined by the following formula: fold change $=2^{-\Delta \Delta \mathrm{Ct}}$, where $\Delta \Delta \mathrm{Ct}=(\mathrm{Ct}$ target gene $-\mathrm{Ct}$ actin gene) transgenic plants ( $\mathrm{Ct}$ target gene - $\mathrm{Ct}$ actin gene) wild-type plants. The following primers were used for the analysis, NtROS2a: ( $5^{\prime}$-CACTTTTGGAAGGGTTGGACA- $\left.3^{\prime}\right)$ and R ( $5^{\prime}$-CGTATGCTGTTGCATGAGGAA- $3^{\prime}$ ), and Actin F: (5'-CGCCCGTCATCGTGCGGTTC- $3^{\prime}$ ) and R: (5'-TCCGCGGGGTCCATGG TCTG-3'). RT-PCR analysis of vegetative tissue (leaf, stem, and root) was conducted using $50 \mathrm{ng}$ of total RNA treated with DNase I. The amplification program 
consisted of an initial step at $42^{\circ} \mathrm{C}$ for $60 \mathrm{~min}, 94^{\circ} \mathrm{C}$ for 5 min, 40 cycles $\left(94^{\circ} \mathrm{C}\right.$ for $15 \mathrm{sec}, 55^{\circ} \mathrm{C}$ for $30 \mathrm{sec}, 72^{\circ} \mathrm{C}$ for $30 \mathrm{sec}$ ), and a final step at $72{ }^{\circ} \mathrm{C}$ for $10 \mathrm{~min}$, and the amplified fragments were loaded on $1.2 \%$ agarose gel.

\section{Germination assays under salt and drought stresses}

All seeds in the following assays were surface sterilized and kept at $4^{\circ} \mathrm{C}$ for $2 \mathrm{~d}$ to break dormancy before subjecting them to any of the experimental treatments. For the germination assay, the tobacco seeds were plated in one-half MS medium (0.6\% agar) added separately with PEG6000 or $\mathrm{NaCl}$, and the number of germinated seeds was counted every day. For root elongation assay, the germinated seeds were first plated upright in MS plates until the roots were about $0.5 \mathrm{~cm}$, then the seedlings were transferred into the same medium supplemented with PEG6000 or $\mathrm{NaCl}$, in the growth chamber. The root lengths were recorded before and after the treatments.

\section{Leaf discs assay and chlorophyll contents in transgenic plants}

Tobacco seeds (Nicotiana tabacum cv Xanthi nc) were grown under controlled conditions having $28^{\circ} \mathrm{C}$ day $/ 25^{\circ} \mathrm{C}$ night temperatures, $14 \mathrm{~h}$ (light) / $10 \mathrm{~h}$ (darkness) in MS medium in a Magenta culture box (Sigma, USA), and 75\% relative humidity. Three weeks after germination, healthy and fully expanded leaves of wild-type and transgenic plants were detached. Leaf discs of about $1 \mathrm{~cm}$ in diameter were cut and floated in 1/2 MS medium containing separately either $250 \mathrm{mM} \mathrm{NaCl}$ or $3 \% \mathrm{H}_{2} \mathrm{O}_{2}$ for $6 \mathrm{~d}$. The treatment was performed in continuous white light at $25^{\circ} \mathrm{C}$. To examine the chlorophyll contents, the leaf discs obtained from transgenic and WT plants were floated in $1 / 2$ MS liquid medium containing $250 \mathrm{mM} \mathrm{NaCl}, 3 \% \mathrm{H}_{2} \mathrm{O}_{2}$ without sucrose (MSH) for $7 \mathrm{~d}$ under light at $25^{\circ} \mathrm{C}$. Measurement of chlorophyll fluorescence was performed according to Aono et al. (1993).

\section{RESULTS}

\section{Characterization of NtROS2a genes}

Two cDNA fragments were initially isolated from tobacco leaves RNA by reverse transcriptase-PCR using a set of degenerate primers which were designed based on the conserved DNA glycosylase domain being known as plant 5-methylcytosine DNA glycosylase proteins (http:// www.chromdb.org). One of the two fragments cloned, designated as Nicotiana tabacum Repressor $\underline{\text { Of }} \underline{\text { Silencing }}$ 2a (NtROS2a), (Fig. 1A) (accession numbers AB281588 for NtROS2a) is $5879 \mathrm{bp}$ long and is highly associated to XP_002267310 (Vitis vinifera) and ABC61677 (A. thaliana). This clone encoded a protein of 1,673 amino acids with predicted molecular mass of $186 \mathrm{kDa}$. A pair-wise comparison of their deduced amino acid sequences with ABC61677 (A. thaliana) showed the similarity of NtROS2a at $32.2 \%$. However, the similarity at the glycosylase domain with $\mathrm{ABC} 61677$ (A. thaliana) was 94.3\% for NtROS2a (amino acid positions, 1,291-1,459). A pair-wise comparison of NtROS2a indicated the similarity of $N t R O S 2 b$ to be $99.6 \%$. Notably, only five out of 1,673 total amino acids (0.4\%) differed between NtROS2a and $N t R O S 2 b$, suggesting them to be isoforms. Clustering starts in the root node with the training and evaluation of 17 DNA glycosylase classifiers (Fig. 1B). The species representing the DNA glycosylase group are divided into two groups under the same parent roots. NtROS2a gene is grouped to other roots compared with genes related to demethylation. This result indicates that NtROS2a is a unique gene related to demethylation. GFP fluorescence in BY-2 cell suspensions was examined after transformation. About $70 \%$ of roundshaped calli that were obtained after the Agrobacteriummediated transformation of BY-2 cells displayed GFP fluorescence intensity sufficient for reliable evaluation of its homogeneity (data not shown). Subcellular localization of NtROS2a gene was analyzed by Agrobacteriummediated transient expression of a NtROS2a-GFP fusion gene in onion epidermal cells (Fig. 2). The cells transformed with NtROS2a-GFP displayed fluorescence specifically in the nucleus, suggesting that NtROS2a is a nucleuslocalized protein.

\section{Gene expression under various stresses}

In plants, NtROS2a play a direct regulatory role in response to multiple signal stimulation. To clarify the potential function of NtROS2a in response to different 
A

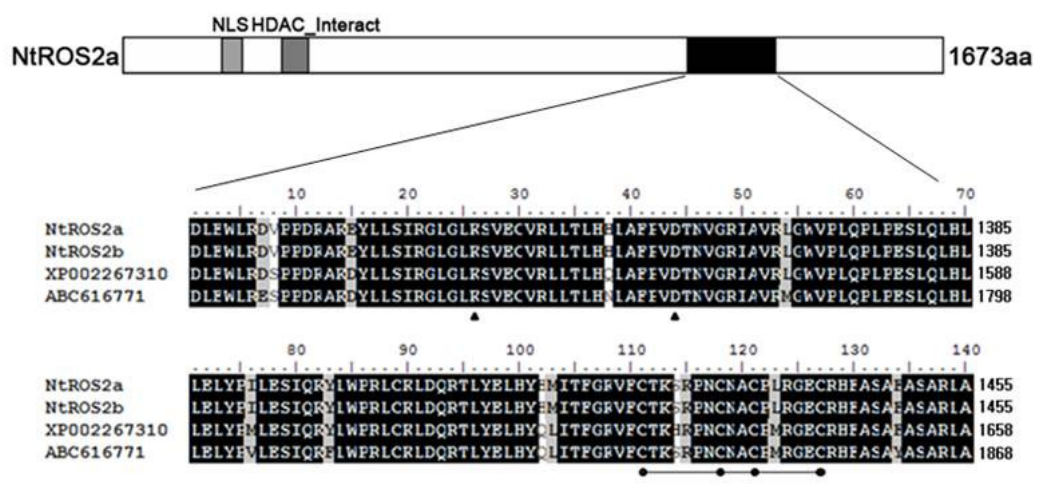

B

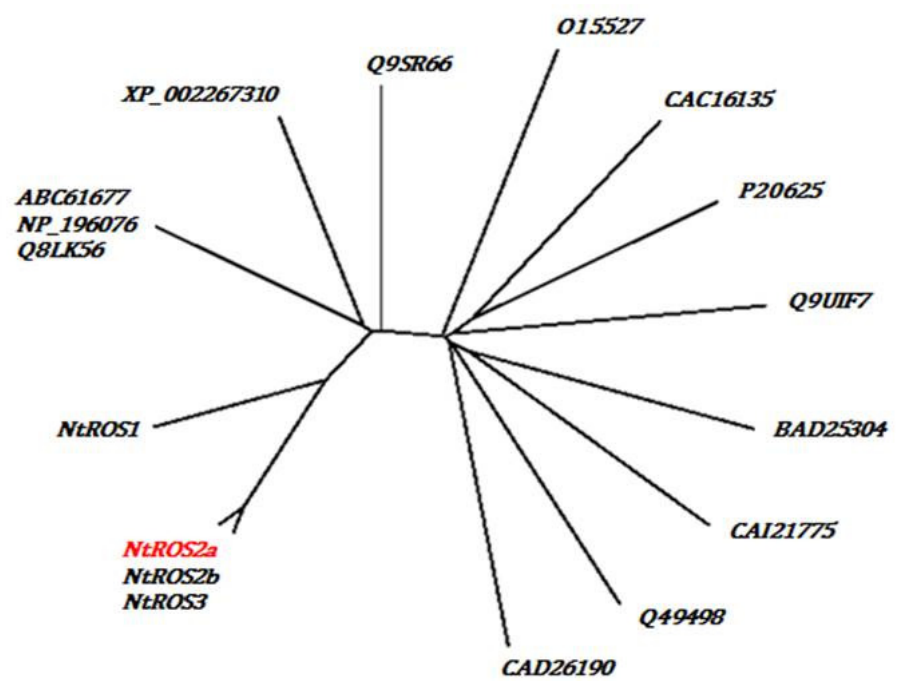

Fig. 1. (A); Alignment of conserved $\mathrm{m}^{5} \mathrm{C}$ DNA glycosylase domain of NtROS2a, AB281588; NtROS2b, AB281589 (Nicotian tabaccum); XP_002267310 (Vitis vinifera); ABC61677 (A. thaliana) Common amino acids among for proteins are indicated by closed box, and grey boxes indicate conservative changes. Conserved lysine and aspartic acid residues in the glycosylase/lyase active site (InterPRO search, IPRO11257) are indicated by closed arrowheads, and four cysteine residues predicted to function in DNA binding are indicated by closed circles. (B); Unrooted phylogenetic tree. Amino acid sequences were aligned using the ClustalW program. Genebank accession numbers areNtROS1, AB281587; NtROS2a, AB281588; NtROS2b, AB281589; NtROS3, AB281590 (N. tabacum); XP_002267310 (Vitis vinifera); Nth1, CAC16135; AtDME, Q8LK56; AtDML2, Q9SR66; AtDML3, Q49498: DME, NP_196076; DEMETER, ABC61677 (A. thaliana); MutY, Q9UIF7 Ogg1, O15527; A2, CAI21775 (Homo sapiens); Nth, P20625 (Escherichia coli); A2 , BAD25304 (Oryza sativa japonica Group); GB-M1,CAD26190 (Encephalitozoon cuniculi GB-M1 Eukaryota; Fungi; Microsporidia; Unikaryonidae; Encephalitozoon).

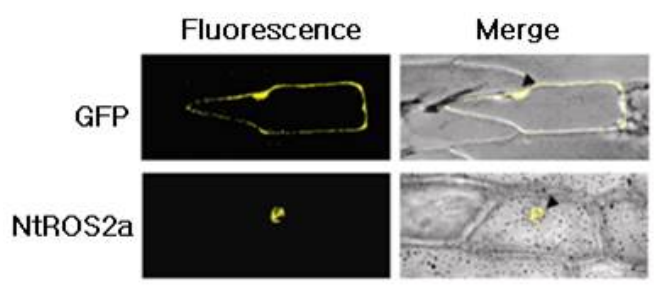

Fig. 2. Cellular localization. Onion epidermal cell layers were bombarded with gold particles coated 35SGFP alone or

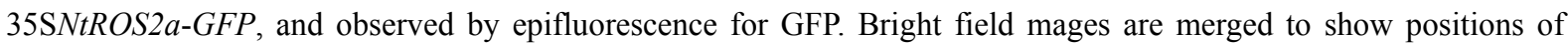
nucleus indicated by arrowheads. 
stimuli, Expression pattern of NtROS2a gene was investigated under various abiotic stresses (Fig. 3). The NtROS2a gene was induced expression after ABA, cold, salt and $\mathrm{H}_{2} \mathrm{O}_{2}$ treatments. NtROS2 $a$ mRNA was accumulated at $6 \mathrm{hr}$. after stresses treatment except for cold. At $8 \mathrm{hr}$. after stresses treatment, the expression level was declined back to the levels at $6 \mathrm{hr}$. treatment. However, there was no significant accumulation of NtROS2a mRNA under cold stress. The lowest expression was observed in plants under normal conditions (data not shown).

\section{Vector construction and transgenic plants}

To generate transgenic plants, NtROS2a cDNA was cloned into the binary expression vector pBI121 under the
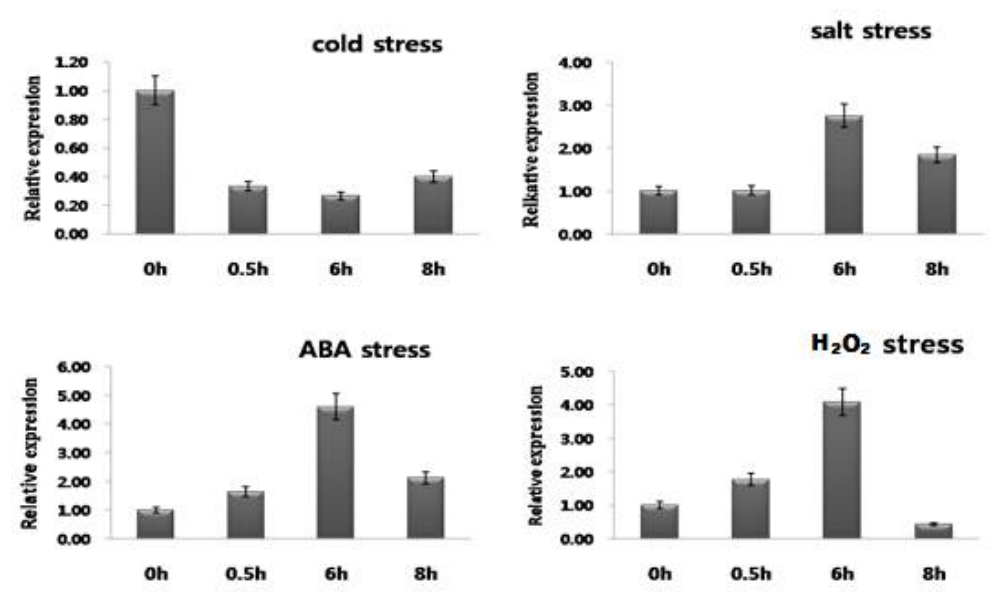

Fig. 3. Expression of $N t R O S 2 a$ in reponse to abiotic stress in tobacco. The real-time qRT-PCR analysis of $N t R O S 2 a$ in tobacco seedlings subjected to abiotic stresses in cluding cold $\left(4^{\circ} \mathrm{C}\right)$, salt $(250 \mathrm{mM} \mathrm{NaCl})$, and $\mathrm{ABA}(100 \mu \mathrm{M}), \mathrm{H}_{2} \mathrm{O}_{2}(3 \%)$ stress. Total RNA was purified from the tobacco seedlings at Three-leaf stage after various treatments and used in real-time qRT-PCR assays.

A

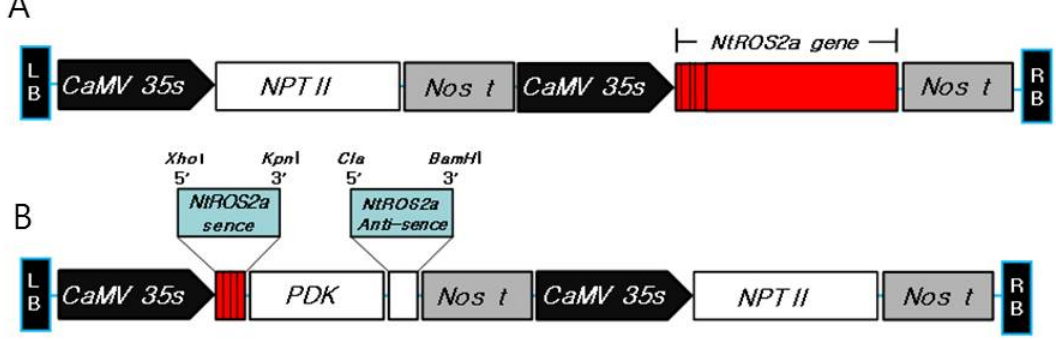

C a

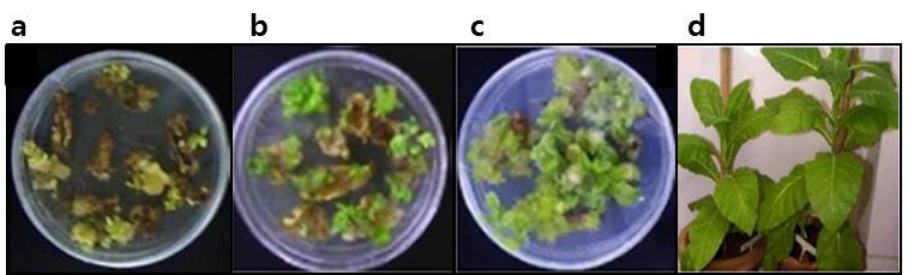

Fig. 4. Ti-plasmid vectors for overexpression and silencing NtROS $2 a$ gene and transgenic plants. (A); Ti-plasmid vector for overexpression of NtROS $2 a$ gene. (B); Ti-plasmid vector for gene silencing (RNAi) of NtROS $2 a$ gene. (C); Transformation with Agrobacterium on MS medium with selectable kanamycin, (a); Survival response of explants in the selection medium after 4 weeks of co-cultivation (b); Appearance of shoot buds from the cut edges of the surviving green explants and development of small multiple shoots (c); Differentiation and elongation of green resistant shoots under selection after 8 weeks of culture (d); Acclimation of transgenic plants. 
control of the $35 \mathrm{~S}$ promoter (Fig. 4A). RNAi vector was designed for directional insertion of PCR products on either side of the PDK intron (Fig. 4B). The NtROS2a gene fragment was amplified through PCR, appended with the restriction sites and cloned sequentially on either side of the intron to become the two arms of the hairpin. The tobacco leaf discs infected with Agrobacterium on MS medium with selectable kanamycin showed callus formation. The callus formation initiated from only the putative transformed leaf discs and the untransformed leaf discs began to yellow after 3-5 days. During the following 5-10 days, the leaf discs turned brown and did not initiate callus formation. The transformed leaflets developed into bright green calli and then the shoots emerged with 3 - 5 leaflets in 25-30 days (Fig. 4C-a, b). The emerging shoots with 3-5 leaflets showed root formation in 20-25 days (Fig. 4C-c). The roots continued to grow in the putative transgenic plants, but the root growth in untransformed plants did not develop (data not shown). All transgenic plants showed normal phenotype. The $T_{1}$ putative transgenic plants were transferred from the 1/2 MS medium to a selectable kanamycin supplemented MS medium. The plantlets remained green and developed elongated roots as they were resistant to kanamycin, while the untransformed plants became yellow while the roots ceased to elongate because of their sensitivity to the antibiotic (Fig. 4C-d). PCR analysis of transgenic lines in $\mathrm{T}_{2}$ generation was confirmed integration to tobacco genome both NtROS2a and nptII gene.

\section{Transcript levels of NtROS2a in the transgenic plants}

The transcript levels of NtROS2a in the transgenic plants
Table 1. Primers sequence used for NtROS $2 a$ analysis.

\begin{tabular}{ll}
\hline \hline \multicolumn{1}{c}{ Primers } & \multicolumn{1}{c}{ Sequence(5'-3') } \\
\hline NtROS2a-RT F & TGTAAGTCTGAGCGAAGAGC \\
NtROS2a-RT R & GGAAAGCTAGGTGGTGAAGT \\
actin-RT F & TACATGTTCACCACCACTGC \\
actin-RT R & AAGCTCCTGCTCGTAGTCAA \\
35s-F & TGAGACTTTTCAACAAAGGGTA \\
NtROS2a-R & ACAATGGGCTCTGGTGTTGC \\
Kana F & ATGATTGAACAAGATGGATTGCAC \\
Kana R & TCAGAAGAACTCGTCAAGAAGGC \\
URP250 & CCAGTTGCTATAAGAGGCAT \\
URP251 & ATCCAAGGTCCGAGACAACC \\
URP253 & CCCAGCAACTGATCGCACAC \\
URP255 & ATGTGTGCGATCAGTTGCTG \\
\hline
\end{tabular}

were determined by RT-PCR analysis using gene-specific primer sets (Table 1). Total RNAs were extracted from leaf of 14-d-old seedlings grown under normal growth conditions. NtROS2a expression level was higher in all pBI121:: NtROS2 $a$ transgenic lines than in the non-transgenic (WT) controls (Fig. 5A). By contrast, the pKANNIBAL::NtROS2a transgenic lines showed lower expression level of $N t R O S 2 a$ gene than in non-transgenic (Fig. 5B).

\section{Transgenic tobacco enhanced Salt- and $\mathrm{H}_{2} \mathrm{O}_{2}$-stress tolerance}

To examine the effect of abiotic stress in transgenic tobacco plants, gene expression patterns were investigated between the transgenic and non-transgenic plants under salt and $\mathrm{H}_{2} \mathrm{O}_{2}$ stress (Fig. 6). NtROS2a transcript was induced by salt- and $\mathrm{H}_{2} \mathrm{O}_{2}$ stress. The leaves of $\mathrm{T}_{2} \mathrm{NtROS} 2 a$
(A)

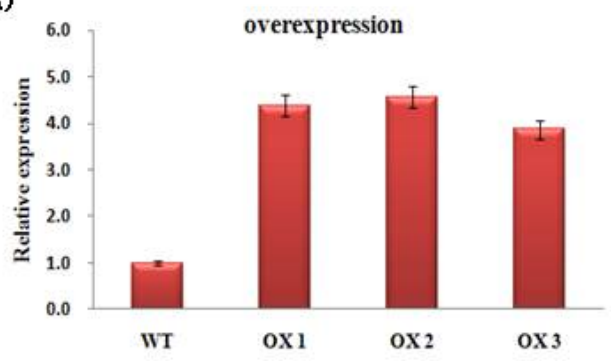

(B)

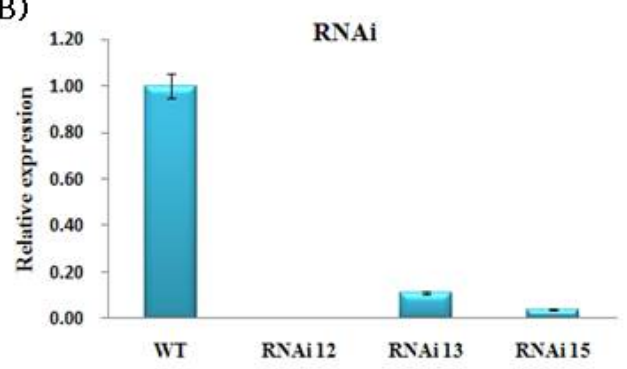

Fig. 5. Quantitative RT-PCR analysis. WT; Wild type tobacco (Nicotiana tabacum cv Xanthi nc), (A); pBI121::NtROS2a (OX lines), (B); pKANNIBAL::NtROS2a (RNAi lines). CT values were calculated using actin expression level as a control. Error bars show the standard error of the mean for three replicate measurements. 

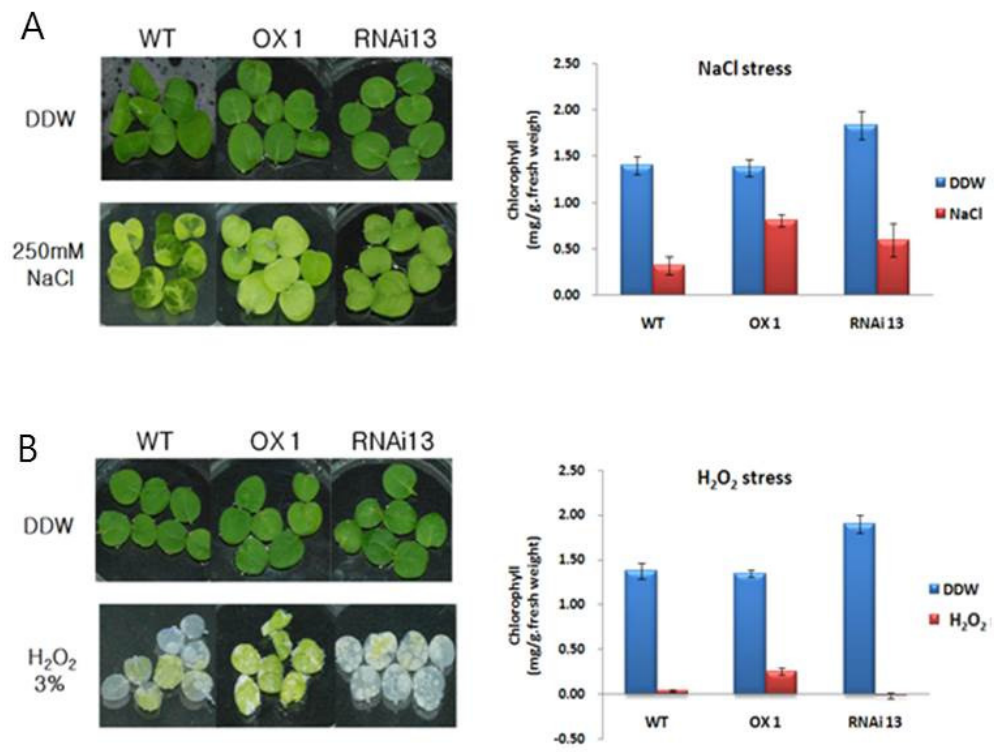

Fig. 6. $\mathrm{NaCl}$ and $\mathrm{H}_{2} \mathrm{O}_{2}$ sensitivity in transgenic plants. (A) and (B) showed the phenotype of leaf discs from the WT plants, OX lines and RNAi lines after incubation in $250 \mathrm{mM} \mathrm{NaCl}$ and $3 \% \mathrm{H}_{2} \mathrm{O}_{2}$ solution for $5 \mathrm{~d}$, and corresponding measurement of chlorophyll contents respectively. Leaf discs floating in water served as the control. The standard deviation is represented by the vertical bar in graph $(n=3)$.

transgenic lines OX 1 and RNAi 13 and non-transgenic WT were incubated at $250 \mathrm{mM} \mathrm{NaCl}$ and $3 \% \mathrm{H}_{2} \mathrm{O}_{2}$ for 5 days. In $\mathrm{NaCl}$, most of WT leaves (83\%) wilted, whereas only $30.7 \%$ seedlings of transgenic line 1 and $24.4 \%$ of line 13 wilted (Fig. 6A). In $\mathrm{H}_{2} \mathrm{O}_{2}$, most leaves of WT (90\%) and transgenic line $13(99 \%)$ were wilted, while only $20 \%$ seedlings of transgenic line 1 showed the symptom (Fig. 6B).

\section{Effects of abiotic stress on rot elongation in transgenic lines}

Transgenic lines (OX 1, RNAi 13) were subjected to simulated osmotic stress, and the effects on root elongation were assessed after germination. Germination in OX 1 lines was clearly higher than that in WT and RNAi 13 (Fig. 7A and B). After $9 \mathrm{~d}$ of $125 \mathrm{mM} \mathrm{NaCl}$ treatment, seed germination in OX 1 line was $40 \%$ which is higher than the $15 \%$ germination in WT. Similarly, the germination percentage in OX 1 lines was twice higher than that in WT after 2\% PEG6000 treatment for $9 \mathrm{~d}$. After $14 \mathrm{~d}$ of the same treatment, the roots of OX 1 line plants were about twice longer than those in wild type and RNAi 13. Interestingly, when subjected to higher concentrations of PEG (2\%) for the same duration, roots of OX 1 line were not only about
$34 \%$ longer than those of wild types but also produced more lateral roots. These results indicate that NtROS2a increases the adaptation to salt and osmotic stress during seed germination and root elongation in tobacco (Fig. 7C). Also, the change of DNA methylation affects the gene expression and stability. Insertion of NtROS2a is expected to cause changes in the genome of recipient plant. Total DNA of transgenic lines was digested with MspI and HpaII, which are unable to cleave the sites $\mathrm{m}^{5} \mathrm{CCGG}$ and $\mathrm{Cm}^{5} \mathrm{CGG}$, respectively. DNA methylation affects was analyzed by RAPD analysis, but there were no different bands amplified (data not shown). This became part of the band overlap in demethylation, or a very specific band that a fragment is considered.

\section{DISCUSSION}

DNA glycosylases are subdivided into four groups according to their substrate specificity: excision of uracil, uracil-containing mismatches, alkylated bases and oxidized bases (Begum et al. 2007). NtROS proteins are structurally related to Arabidopsis ROS1 and DME, which belong to a 
A

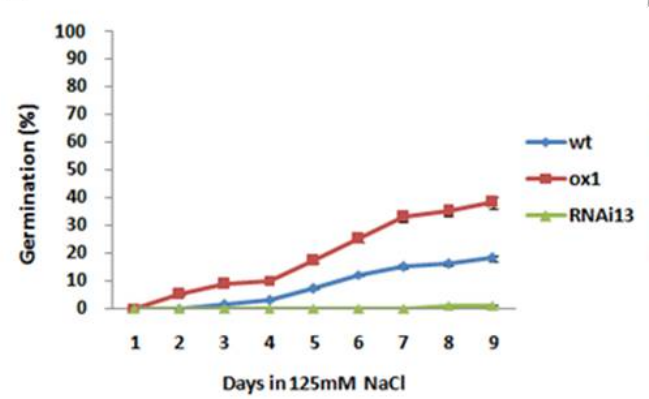

B

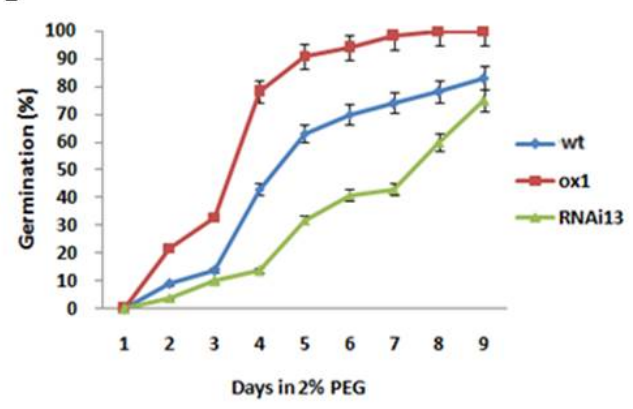

$\mathrm{C}$

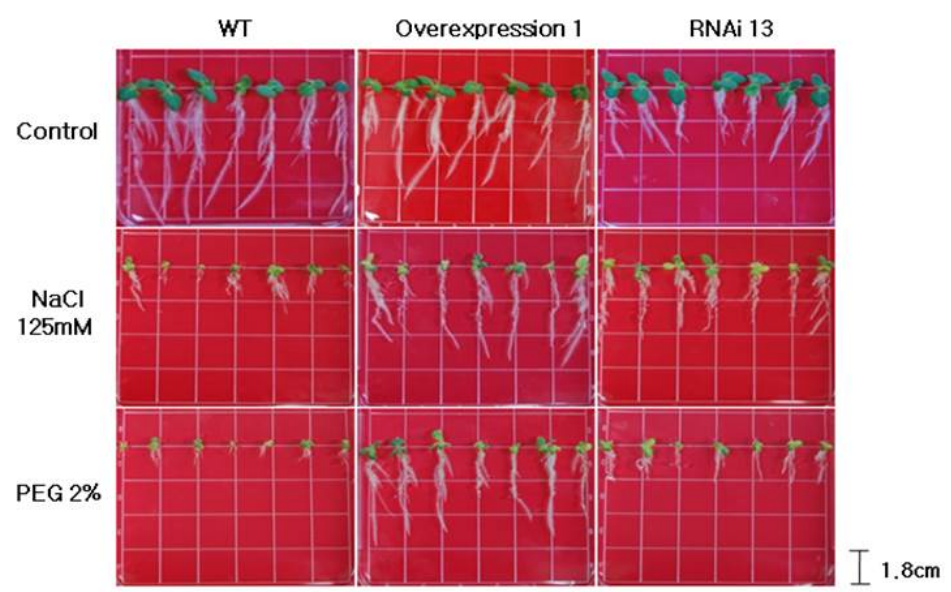

Fig. 7. Germination assay under salt and osmotic stresses in transgenic lines (A); $125 \mathrm{mM} \mathrm{NaCl}$ stresses, (B); $2 \%$ PEG stresses. (C); Root elongation under salt and osmotic stresses in transgenic lines. Root growth under $125 \mathrm{mM} \mathrm{NaCl}$ and $2 \%$ PEG for 2 weeks after germination.

large family of uracil-containing mismatch DNA glycosylases. However, apart from the $\mathrm{m}^{5} \mathrm{C}$ DNA glycosylase domain and regions at the carboxyl-terminus, their similarity was low, suggesting specific function of NtROS proteins. Since NtROS1 and NtROS2a were shown to possess $\mathrm{m}^{5} \mathrm{C}$ removal activity, and to be localized in nucleus, it is conceivable that they are closely associated with DNA and engaged in DNA demethylation. Conserved lysine and aspartic acid residues located in the helix-hairpin-helix domain in DNA glycosylases (Krokan et al. 1997) and four cysteine residues adjacent to the DNA glycosylase domain were also shown in NtROS proteins. The latter cluster is considered to play a role in DNA binding. NtROS proteins also possess nuclear localization signal and histone deacetylase interacting domains (http:// smart.embl- heidelberg.de/) (Fig. 1), suggesting them to localize in nucleus and to interact with DNA or chromatin (Gehring et al. 2006). In our studies, subcellular localization of NtROS2a gene was localized a nucleus protein (Fig. 2).
Their induction profile upon abiotic stresses is indicative, as DNA glycosylases are considered to deal with oxidative damages, which are commonly caused by reactive oxygen species (Choi and Sano 2007; Begum et al. 2007). The NtROS2a gene was induced expression after ABA, cold, salt and $\mathrm{H}_{2} \mathrm{O}_{2}$ treatments. NtROS2a mRNA was accumulated at $6 \mathrm{hr}$. after stresses treatment except for cold. At $8 \mathrm{hr}$. after stresses treatment, the expression level was declined back to the levels at $6 \mathrm{hr}$. treatment. However, there was no significant accumulation of NtROS2a mRNA under cold stress (Fig. 3). To cope with such damages, a set of genes must be expressed to repair and/or strengthen defense reactions. If these genes are locked by methylation under non-stressed condition, demethylation is absolutely necessary to globally switch them on. It is tempting to speculate that NtROS proteins participate in this task, thereby finely adjusting gene expression through methylation/demethylation pathways. This study showed a close correlation between 
demethylation and expression of a tobacco gene encoding a glycerophosphodiesterase-like protein upon exposure to abiotic stresses. This speculation is in accordance with the present finding, showing that NtROS2a is distantly related to other members, and localized not only at cell surface (plasma membrane) but also in nucleus, suggesting a novel, so far unknown biological functions. In healthy leaves grown under non-stressed conditions, NtROD2a was not expressed, and its coding region was found to be heavily methylated. Upon exposure to abiotic stress, its transcripts were induced and genomic locus was partly demethylated, while upon biotic stress, neither transcripts nor demethylation were induced. In this report, transgenic lines (OX 1, RNAi 13) were subjected to simulated osmotic stress, and the effects on root elongation were assessed after germination. Germination in OX 1 lines was clearly higher than that in WT and RNAi 13 (Fig. 7). After $9 \mathrm{~d}$ of $125 \mathrm{mM} \mathrm{NaCl}$ treatment, seed germination in OX 1 line was $40 \%$ which is higher than the $15 \%$ germination in WT. This strengthened the close correlation between gene expression and methylation, and shows clear demethylation activity towards $\mathrm{m}^{5} \mathrm{C}$ in DNA and ubiquitously expressed in plant tissues (Aguis et al. 2006). Its involvement in stress response has yet to be confirmed, but the present findings indicate that this possibility warrants attention.

\section{ACKNOWLEDGMENTS}

This work was supported by a research grant from Hankyong National University in the year of 2014

\section{REFERENCES}

Aguis F, Kapoor A, Zhu JK. 2006. Role of the Arabidopsis DNA glycosylase/lyase ROS1 in active DNA demethylation. Proc. Natl. Acad. Sci. USA 103: 11796-11801.

Aono M, Kubo A, Saji H, Tanaka K, Kondo N. 1993. Enhanced tolerance to photooxidative stress of transgenic Nicotiana tabacum with high chloroplastic glutathione reductase activity. Plant Cell Physiology 34: 129-135.

Begum NA, Izumi N, Nishikori M, Nagaoka H, Shinkura R,
Honjo T. 2007. Requirement of non-canonical activity of uracil DNA glycosylase for class switch recombination.

J. Biol. Chem. 282: 731-742.

Bird AP. 2002. DNA methylation patterns and epigenetic memory. Genes Dev. 16: 6-21.

Cao X, Jacobsen SE. 2002. Locus-specific control of asymmetric and $\mathrm{CpNpG}$ methylation by the DRM and CMT3 methyltransferase genes. Proc. Natl. Acad. Sci. USA 16491-16498.

Chakrabarty D, Yu KW, Paek KY. 2003. Detection of DNA methylation changes during somatic embryogenesis of Siberian ginseng (Eleuterococcus senticosus). Plant Sci. 165: 61-68

Chomczynski P, Sacchi N. 1987. Single Step Method of RNA Isolation by Acid Guanidinium Thiocyanate-PhenolChloroform Extraction. Anal. Biochem. 162: 156-159.

Choi CS, Hiroshi Sano. 2007. Abiotic-stress induces demethylation and transcriptional activation of a gene encoding a glycerophosphodiesterase-like protein in tobacco plants. Mol. Genet. Genomics 277: 589-600.

Demeulemeester MAC, Van Stallen N, De Proft MP. 1999. Degree of DNA methylation in chicory (Cichorium intybus L.). influence of plant age and vernalisation. Plant Sci. 142: 101-108.

Finnegan EJ, Peacock WJ, Dennis ES. 1996. Reduced DNA methylation in Arabidopsis thaliana results in abnormal plant development. Proc. Natl. Acad. Sci. USA 93: 84498454.

Gehring M, Huh JH, Hsieh TF, Penterman J, Choi Y, Harada JJ, Goldberg R, Fischer RL. 2006. DEMETER DNA glycosylase establishes MEDEA polycomb gene selfimprinting by allele-specific demethylation. Cell 124: 495-506.

Kankel MW, Ramsey DE, Stokes TL, Flowers SK, Haag JR, Jeddeloh JA, Riddle NC, Verbsky ML, Richards EJ. 2003. Arabidopsis MET1 cytosine methyltransferase mutants. Genetics 163: 1109-1122.

Krokan HE, Standal R, Slupphaug G. 1997. DNA glycosylases in base excision repair of DNA. Biochem. J. 325: 1-16.

Law JA, Jacobsen SE. 2010. Establishing, maintaining and modifying DNA methylation patterns in plants and animals. Nat. Rev. Genet. 11: 204-220.

Li E, Bestor TH, Jaenisch R. 1992. Targeted mutation of the DNA methyltransferase gene results in embryonic lethality. Cell 69: 915-926. 
Livak KJ, Schmittgen TD. 2001. Analysis of relative gene expression data using real-time quantitative PCR and the $2^{-\triangle \triangle \mathrm{Ct}}$ method. Methods 25: 402-408.

Morales-Ruiz T, Ortega-Galisteo AP, Ponferrada-Marin MI, Martinez-Macias MI, Ariza RR, Roldan-Arjona T. 2006. DEMETER and REPRESSOR OF SILENCING 1 encode 5-methylcytosine DNA glycosylases. Proc. Natl. Acad. Sci. USA 103: 6853-6858.

Murashige T, Skoog F. 1962. A revesed medium for rapid growth and bioassays with tobacco cultures. Physiol. Plant 15: 473-497.

Reik W, Dean W, Walter J. 2001. Epigenetic reprogramming in mammalian development. Science 293: 1089-1093.

Ronemus MJ, Galbiati M, Ticknor C, Chen J, Dellaporta SL. 1996. Demethylation-induced developmental pleiotropy in Arabidopsis. Science 273: 654-657.

Stancheva I, Meehan RR. 2000. Transient depletion of xDnmt1 leads to premature gene activation in Xenopus embryos. Genes Dev. 14: 313-327.
Sano H, Kamada I, Youssefian S, Katsumi M, Wabiko H. 1990. Asingle treatment of rice seedlings with 5-azacytidine induces heritable dwarfism and under methylation of genomic DNA. Molecular Genetics and Genomics 220: 441-447.

Steward N, Ito M, Yamakuchi Y, Koizumi N, Sano H. 2002. Periodic DNA methylation in maize nucleosomes and demethylation by environmental stress. J. Biol. Chem. 277: 37741-37746.

Wada Y, Miyamoto K, Kusano T, Sano H. 2004. Association between up-regulation of stress-responsive genes and hypomethylation of genomic DNA in to tobacco plants. Mol. Genet. Genomics 271: 658-666.

Zhang X, Yazaki J, Sundaresan A, Cokus S, Chan SW, Chen H, Henderson IR, Shinn P, Pellegrini M, Jacobsen SE et al. 2006. Genome-Wide high-resolution mapping and functional analysis of DNA methylation in Arabidopsis. Cell 126: 1189-1201. 